\title{
Corrigendum: Reactive Oxygen Species in Pathogen Clearance: The Killing Mechanisms, the Adaption Response, and the Side Effects
}

\author{
Hao Li, Xuedong Zhou, Yuyao Huang, Binyou Liao, Lei Cheng ${ }^{*}$ and Biao Ren* \\ State Key Laboratory of Oral Diseases, National Clinical Research Center for Oral Diseases, West China Hospital of \\ Stomatology, Sichuan University, Chengdu, China
}

Keywords: reactive oxygen species, secondary damage, metabolism remodeling, virulence, antibiotic resistance, antibiotic tolerance

\section{A Corrigendum on}

\section{OPEN ACCESS}

Edited and reviewed by: Kirkwood M. Land,

University of the Pacific, United States

${ }^{*}$ Correspondence:

Lei Cheng

chenglei@scu.edu.cn

Biao Ren

renbiao@scu.edu.cn

Specialty section:

This article was submitted to Antimicrobials, Resistance and

Chemotherapy,

a section of the journal

Frontiers in Microbiology

Received: 24 March 2021 Accepted: 23 April 2021 Published: 13 May 2021

Citation:

Li H, Zhou X, Huang Y, Liao B,

Cheng $L$ and Ren B (2021) Corrigendum: Reactive Oxygen

Species in Pathogen Clearance: The Killing Mechanisms, the Adaption Response, and the Side Effects.

Front. Microbiol. 12:685133. doi: 10.3389/fmicb.2021.685133
Reactive Oxygen Species in Pathogen Clearance: The Killing Mechanisms, the Adaption Response, and the Side Effects

by Li, H., Zhou, X., Huang, Y., Liao, B., Cheng, L., and Ren, B. (2021). Front. Microbiol. 11:622534. doi: $10.3389 /$ fmicb.2020.622534

In the original article, there was an error. The original article read: Recent study shows that host ROS can be sensed as a chemorepellent in H. pylori by the chemoreceptor TlpD, which initiates chemotaxis to promote gastric gland colonization (Collins et al., 2018; Perkins et al., 2019).

A correction has been made to the section, Thrive Under ROS Conditions by Metabolic Remodeling. The corrected sentence is below:

Recent studies showed that ROS could be sensed in H. pylori by the chemoreceptor TlpD. Host oxidants hypochlorous acid $(\mathrm{HOCl})$ could act as a chemoattractant by reversibly oxidizing TlpD that inactivates the chemotransduction signaling complex (Perkins et al., 2019). While $\mathrm{H}_{2} \mathrm{O}_{2}$ could act as a chemorepellent which initiates chemotaxis through TlpD to promote gastric gland colonization (Collins et al., 2018).

The authors apologize for this error and state that this does not change the scientific conclusions of the article in any way. The original article has been updated.

\section{REFERENCES}

Collins, K. D., Hu, S., Grasberger, H., Kao, J. Y., and Ottemann, K. M. (2018). Chemotaxis allows bacteria to overcome host-generated reactive oxygen species that constrain gland colonization. Infect. Immun. 86:e00878-17.

Perkins, A., Tudorica, D. A., Amieva, M. R., Remington, S. J., and Guillemin, K. (2019). Helicobacter pylori senses bleach $(\mathrm{HOCl})$ as a chemoattractant using a cytosolic chemoreceptor. PLoS Biol. 17:e3000395. doi: 10.1371/journal.pbio.3000395

Copyright $(2021 \mathrm{Li}$, Zhou, Huang, Liao, Cheng and Ren. This is an open-access article distributed under the terms of the Creative Commons Attribution License (CC BY). The use, distribution or reproduction in other forums is permitted, provided the original author(s) and the copyright owner(s) are credited and that the original publication in this journal is cited, in accordance with accepted academic practice. No use, distribution or reproduction is permitted which does not comply with these terms. 